Revista de la red interuniversitaria de estudios sobre las literaturas rioplatenses contemporáneas en Francia

23 | 2021

La vereda de enfrente. Cruces entre las literaturas argentina y chilena del siglo $\mathrm{XX}$

\title{
Puntuación y ruido en la poesía política de los noventa
}

Ponctuation et bruit dans la poésie politique des années 1990

Punctuation and noise in the political poetry of the nineties

\section{Ana Porrúa}

\section{OpenEdition}

\section{Journals}

Edición electrónica

URL: https://journals.openedition.org/lirico/11245

DOI: $10.4000 /$ lirico. 11245

ISSN: 2262-8339

Editor

Réseau interuniversitaire d'étude des littératures contemporaines du Río de la Plata

Referencia electrónica

Ana Porrúa, «Puntuación y ruido en la poesía política de los noventa», Cuadernos LIRICO [En línea], 23 |

2021, Publicado el 17 diciembre 2021, consultado el 07 enero 2022. URL: http://

journals.openedition.org/lirico/11245 ; DOI: https://doi.org/10.4000/lirico.11245

Este documento fue generado automáticamente el 7 enero 2022.

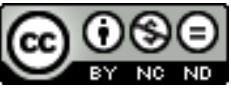

Cuadernos LIRICO está distribuido bajo una Licencia Creative Commons Atribución-NoComercialSinDerivar 4.0 Internacional. 


\title{
Puntuación y ruido en la poesía política de los noventa
}

Ponctuation et bruit dans la poésie politique des années 1990

Punctuation and noise in the political poetry of the nineties

\section{Ana Porrúa}

\author{
No, \\ si puedes quedarte \\ pero sucede \\ es decir la casa está \\ digamos que no hay \\ mucho por donde una \\ o dos puedan veamos \\ es que estoy con un ritmo \\ Yanko González, Alto Volta (2007) \\ Bienvenida perdida Eme \\ a la aldea de los huraños \\ las hormigas cuentan las horas \\ las arañas cuentan los años. \\ Martín Gambarotta, Para un plan primavera (2011)
}

\section{Escena tonal}

1 En abril de 2005 tuvieron lugar las Jornadas de Poesía Joven Juan L. Ortiz en Chile, organizadas por el Ministerio de Relaciones Exteriores, Comercio Internacional y Culto argentino. ${ }^{1}$ El objetivo de estas reuniones (que se dieron en otros países de América Latina) era el encuentro de poetas chilenos y argentinos. La primera lectura fue en el Café de las Artes de la ciudad de Santiago. Los poetas convocados fueron: Malú Urriola, Víctor López Zumelzu, Javier Bello, Sergio Raimondi y Martín Gambarotta. Traigo hasta aquí un segmento de esa lectura que juntó a Javier Bello y a Gambarotta, para pensarla como escena en los términos de Rancière, como "una pequeña máquina óptica" y 
auditiva (2013: 11) que permite revisar los lazos de una comunidad sensible, la posición de los cuerpos y las voces en relación al poema o la poesía.

2 La poesía de Bello y la de Gambarotta no se parecen en nada, van por caminos y tradiciones absolutamente diferentes. Cito unos versos para ponerle el oído al fraseo; primero, de un poema al azar de Javier Bello, de Las jaulas (1998):

Yo vivía encerrado en un presentimiento,

yo sabía que mi abuelo iba a morir ese mes de diciembre.

No tiene olor a nada la muerte,

la muerte no tiene olor a nada ni se anuncia con rosas.

Cuando me acerqué a la cama no estaba allí sentada,

no estaba allí la muerte, no estaba allí la muerte detrás de la muralla blanca,

delante de la muralla blanca.

Yo vivía encerrado en un presentimiento

Es fácil ver la centralidad de la metáfora, aún después del anuncio narrativo; pero sobre todo, es fácil escuchar la cadencia que va armando la repetición en la que necesariamente el oído hace pie (aunque leamos en silencio) para recuperar, para que una palabra o varias vuelvan a sonar y marquen su presencia sonora, decididamente melódica. Voy ahora hacia un poema de Gambarotta, de Seudo (2000): "Una cosa es sacarla y otra usarla// Una cosa es decir/ helechos que crecen en la pared/y otra es tu mujer/ con zapatos de hombre" (14). En este inicio, puede verse el resultado de hacer trizas un contexto para el poema: frases sueltas, pequeñas banalidades con el tono de la sentencia; el corte y la brevedad como armado de una pieza que parece provenir de un movimiento forzoso o forzado.

Pero volvamos a mi escucha de ese día, porque un estilo no envía siempre a un modo de leer que lo acompaña simétricamente. Bello leyó en la estela de Neruda, un modo de leer de pregnancia extrema, que acentúa el ritmo (me atrevería a decir que la métrica, aun cuando se trate de versos libres). Bello canta, hace del poema una pieza autónoma que resuena en el espacio y ocupa el aire sin perder contornos. Bello coloca la voz en situación de poesía, bajo la convicción de que el poema se sale del murmullo y los tonos públicos. Luego leyó Gambarotta, una combinación de poemas de Seudo, su segundo libro, ya mencionado. No se escuchaba: los ojos clavados en el papel, una voz baja, como metida para adentro. No, no era una voz íntima, la que hace del poema un objeto bajo el sesgo del secreto, o de la lectura en voz alta un fantasma disminuido de ese poema que parece enlazado de manera indisoluble a la lectura en silencio. Era una lectura parca, pegada a la boca, sin capacidad de expansión. Habría que agregar, además, que ante los avisos y las solicitudes de que se acerque al micrófono o levante la voz, Gambarotta permaneció, obstinado, en esa performance, decidido a no luchar con el sonido ambiente. El café fue convirtiéndose en un espacio silencioso y aun así hubo que forzar la escucha y acercar las sillas que terminaron casi pegadas a la mesa que los reunía.

La escucha arrojó, en ese momento, un carácter de debate o contestación. Si Bello había dejado el poema reluciente en el universo sonoro de la poesía, Gambarotta colocó su voz a ras del suelo. ¿Qué se oía en esa performance de un dueto desparejo?: tradiciones de lectura, ya lo dije, porque en esa época, muy pocos poetas argentinos trabajaban con el poema como una partitura que se activa en la voz, en la lectura pública. ${ }^{2}$ También, aunque sea obvio decirlo, ideas de la poesía o del poema. No se trata entonces de la escena como ilustración, sino de escuchar en ese encuentro las conexiones de un fragmento del campo poético, sus asimetrías y los lugares, los posicionamientos del poema que arman una secuencia con las posiciones de la voz y las elecciones de la 
puesta en voz. Bello, claramente, hace del sonido una forma del sentido: su modo de leer nos lleva, por momentos, a escuchar más el fraseo, las tonalidades y los crescendos que aquello que dice el poema. La pequeña máquina que se montó ese día puede ser recuperada en términos de diatriba tonal porque la voz de la poesía de Bello permitió escuchar a Neruda, e incluso la tradición del poema recitado, que tiene una larga historia. A su vez, Gambarotta exageró un tono, un modo de leer. O mejor, Gambarotta decidió interpelar la escucha sacando la lectura de contexto, negando, casi, la versión sonora del poema. No cualquier versión sonora, porque la lectura sería otra si no hubiese leído antes Bello. Nunca escuchamos en el vacío, siempre oímos la relación entre las voces, los tonos, que en este caso ocuparon dos extremos del espectro auditivo. $^{3}$

6 Nadie que lea poesía está exento de las grabaciones de Neruda que, por cierto, circularon de una manera desmesurada para la poesía: no era difícil escuchar en la puesta en voz de Bello esa puntuación tan particular. Luego, la escena termina de armarse filtrada por cada oído. Debajo, detrás o por arriba de ambas piezas, para un oído argentino, había otra puntuación: de gran evidencia en el caso de la performance de Bello, pero también marcando una diferencia en el caso de Gambarotta. Porque la voz de la época, al menos en Argentina (la poesía tiene voces de época, no sólo poemas que hablan de una época) era, sin dudas, la de Fabián Casas. Poemas con un fraseo narrativo, pegado a su escritura, prácticamente sin variabilidad tonal, sin solemnidad, pero acercándose, por momentos, a la sentencia del verso en el que brilla la condensación de una idea. ${ }^{4}$ Podríamos pensar que en esa escena que parte en dos la audición, de manera irreconciliable, también resonaron faltas, la de las lecturas de Nicanor Parra, por ejemplo, que había armado un contrapunto similar con los modos de leer/ recitar de Neruda. No traigo esta escena aquí para ponerle nombre y apellido a una escucha sino para revisar, en todo caso, la puntuación en una línea habilitada por Peter Szendy, en tanto una escucha es siempre al menos doble (2003), (escuchamos en la puesta de Gambarotta lo que falta) pero también porque ciertas escuchas revelan el stigma, esa forma de la puntuación que marca las voces con un sesgo reconocible, que salta al oído y articula la tradición a la vez que se transforma en una marca de identidad e incluso de propiedad. ${ }^{5}$

7 Siguiendo los tonos, sobre el final de las Jornadas de Poesía Juan L. Ortiz, una mesa reunió, en el Espacio Balmaceda de Santiago de Chile, a Yanko González Cangas y Sergio Raimondi: ahí aparecieron dos puntuaciones distintas, si las incluimos en el contexto de la primera lectura indagada. Una interpelación directa de la escucha, una marcación diversa y extrema. La voz interroga, propone, sentencia, despliega la frase con cierta vehemencia. El poema estaba funcionando, en este dueto, sobre una base melódica y rítmica similar. Ese 26 de abril, Yanko González leyó un poema -"mercat de las flores"que reescribe uno de Seudo de Martín Gambarotta; desde allí, en ese contrapunto que luego retomaré, también puede pensarse esta relación que proponemos para indagar un momento de reunión entre la poesía chilena y la argentina contemporáneas.

\section{Acá/ Aquí : Allá/ Allí}

8 Me interesan, en este caso, algunos hitos del contacto entre la poesía argentina y chilena en los 90 y los 2000 que describiré sumariamente a la vez que focalizo un corpus: Punctum (1996) de Martín Gambarotta y Metales pesados (1998) de Yanko 
González Cangas. A los festivales ya mencionados habría que sumar la recepción de la poesía chilena en revistas argentinas como la Vox virtual o el Diario de poesía, y de la poesía argentina reciente, en la chilena El Matadero.

Marcaría en esa cartografía de idas y vueltas, dos puntas cronológicas. En 2009, la editorial chilena La calabaza del diablo publica Refrito de Martín Gambarotta, un libro en el que mezcla y reordena poemas de Seudo (2000) y Relapso/ Angola (2005). Bajo una operativa similar, Vox publicó en 2008 Me tradujo González, que recupera poemas de Alto Volta (2007) y algunos inéditos. Sin embargo, hay una sincronía saliente en los noventa cuando poesía.com, un sitio editado por Martín Gambarotta y Emiliano Pérez Pena, publica Metales pesados de Yanko González completo a solo un año de su aparición bajo el sello El Kultrún. ${ }^{6}$

10 La circulación de libros, entonces, el mano a mano (se destaca como hito la llegada de Germán Carrasco a Buenos Aires en el 2000 con ejemplares de nuevos poetas chilenos y el posterior envío a Chile de ejemplares de argentinos), las lecturas recíprocas, los festivales, los sitios y las revistas, serán la trama sobre la que se construye otro hito importante, Zur Dos. Última poesía latinoamericana (2004), publicada en Argentina por Paradiso editorial, con un epílogo del poeta argentino Edgardo Dobry. ${ }^{7}$ Porque Zur Dos es la antología de dos poetas de la última poesía chilena, Yanko González y Pedro Araya, que han atravesado estos circuitos, que han intervenido e intervienen más fuertemente al publicar la selección, en la construcción de ciertas líneas poéticas, aquellas en las que el significante tiene un peso, no por experimental; en las que aparece una voz desaforada, "zurda" dirán los antologadores (porque va en contra de ciertos fraseos, pero también de algunos temas poéticos y de la consagración institucional de la poesía y su asociación a un mercado de lectores singulares). Zurdos es, dicen Araya y González en el prólogo, "Zurdas \& reversas", el espacio en que "las tribus se encontrarán cotejando sus lenguas" y en que estas lenguas se proponen como "un castellano (...) apenas visto" (12). (Porrúa 2011: 283-297).

11 De Zur Dos destaco ahora que la selección de Martín Gambarotta abre con un pequeño fragmento de Punctum, parte de la biografía de Sid Vicius y luego incluye poemas de Seudo. El cierre que eligen Araya y Yanko González es uno de los textos en prosa de este libro, cuyo comienzo es:

En el asiento de adelante: los artistas; en el de atrás: los trabajadores. Sin ser ninguna de las dos cosas iba en el asiento de atrás haciéndose el trabajador, el huelguista, pensando cómo hacer plata desnudo. En su cabeza destellaba, repiqueteaba, estallaba lo disléxico, lo inconexo, lo caótico, lo yuxtapuesto a lo industrial, lo verdaderamente enmohecido (Seudo: 84)

12 En aquel encuentro de 2005, el de las Jornadas de Poesía Joven Juan L. Ortiz, Yanko González abre su lectura en el Balmaceda, con Gambarotta como público, y lee "mercat de las flores":

en el asiento de adelante: los gambarotta, en el de atrás: los gonzález. sin ser ninguno de los dos iba tirado atrás

haciéndose por último el gonzález (Alto Volta: $\mathrm{W}$ )

13 Casi una performance topográfica, cuyo guion, leído a la letra, produce un pasaje de artista a Gambarotta y de trabajador a González. Un plural, en ambos casos minorizado, porque los apellidos están con minúscula, que se articula como tipología. Lo que hace Yanko González es pasar a Gambarotta de asiento y quedarse él en el lugar de los trabajadores. El gesto tiene algo de gag si lo imaginamos, y hace del reparto de los roles una división tajante entre trabajadores (muchos) y artistas. ${ }^{8}$ En Seudo de Gambarotta: 
un supuesto viaje a Brasil y la confusión de las comidas (el té con vainilla/ la cashasha y la caipirinha, el pescado frito); entre lo que se conoce y lo que no se sabe -cómo preparar esos licores- para volver a lo que se conoce y la duda de los señalamientos o los pasos. La frase final es, en este sentido, casi un manifiesto: "Una mera cuestión de método: cada uno fríe su pescado como más le gusta". En el poema de Yanko González, el que sale del auto "en el bareto" escucha que "le insultan le mentan el coño la madre./ disimula, sigue sin más silbando por su marcha"; "lo disléxico, lo inconexo, lo caótico, lo yuxtapuesto" que sonaba, "repiqueteaba, estallaba" en la cabeza del sentado atrás del texto de Gambarotta se transforma en insulto, y la duda del descolocado en algo parecido a la tragedia, cuando leemos sobre el final de "mercat de las flores": "pero por dentro está muriendo// O QUÉ PENSABAS." Tal vez en ese paso de la cabeza al cuerpo (dos adentros distintos) también hay algo más para leer en el pase de lugar que imprime González a Gambarotta.

\section{La experiencia puntuada}

Recupero en principio la idea de escena tonal, pero ahora en la lectura de Punctum (1996) de Martín Gambarotta y Metales pesados de Yanko González (1998). Dije alguna vez que la textura de Punctum es la del fragmento (Porrúa 2000) y sin embargo, la relación de esta forma de la suspensión con aquello que se narra (muy pocas veces quienes hablan lo hacen en primera persona) asume una forma, la del corte, la interrupción asociada por el mismo Gambarotta con un ritmo cuando habla de Punctum, cuya modulación es la de la "arritmia" (contra la musiquita fácil, dice) (2015: s/n); el corte como lo entiende Raimondi, como una patología de la lengua: la lengua del afásico o el disléxico recorre el libro dando cuenta, sigo la línea de su artículo "El sistema afecta la lengua", de la persistencia de un orden dictatorial en la lengua presente y la aparición segmentada del pasado, residuos de otro tiempo:

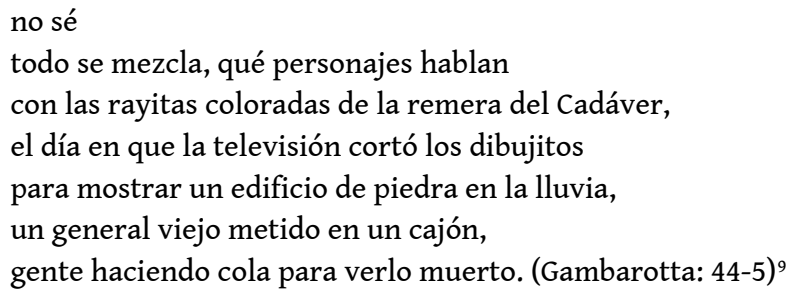

En realidad, esta temporalidad perforada que parece responder a un ojo parpadeante, un ojo defectuoso que intenta ajustar lo que ve, lejos de un ordenamiento de los hechos o hitos claves de la historia de los setenta argentinos o del liberalismo de los noventa, durante el menemismo, arroja escenas que se mueven en una zona diacrónica, aunque la indeterminación sigue siendo su marca: jóvenes que escuchan heavy metal pero han sido parte de la UOM (Unión de Obreros Metalúrgicos), que escuchan trash o punk pero pertenecieron a la izquierda peronista. Una puntuación que puede pensarse a partir del punctum barthesiano, de aquello que se opone al studium (1990: 65 y ss): una experiencia social puntuada a partir de sus zonas ciegas, un ritmo diferente, anómalo, que habilita un espaciamiento entre momentos históricos y a la vez los junta: el punk marca las ideas revolucionarias, pero también lo que queda de los setenta marca a unos jóvenes punk, o más bien a unos jóvenes heavy metal, que se mueven y hablan con dificultad, que están y no están, que permanecen estáticos o caminan bajo el cielo óxido/ y el 
alumbrado lechoso de la calle" (81), cuando "la escena ansiosa se desarrolla sin tiempo verbal" (Gambarotta: 82).

La visibilidad está alterada ${ }^{10}$ y el ojo es lo que manda en Punctum, es lo puntuado o lo que puntúa. Sin embargo, la modulación de la arritmia -de ese que tiene "un orificio cabeza de alfiler/ en una cavidad del corazón" (Gambarotta: 7)- también envía, aunque con dificultad, a la escucha o al sonido. Se escucha esa arritmia en la estructura del poema; cada parte -son 39-, supone cambios de objetos pero asimismo de registros: desde el más narrativo que recupera segmentos de la historia de un o unos personajes expulsados del mundo del trabajo, del mundo de la política, hasta el que arma escenas diminutas y sueltas de la narración, o el más ensayístico, como en el caso de la biografía segmentada de Sid Vicius, enunciada justamente como "idea para un ensayo" (Gambarotta: 13), pero también de la indagación etimológica de los términos como trash o las derivaciones de enfermo en inglés (Gambarotta: 24 y 60). Pulso breve y pulso extenso, pulso acelerado o lento marcan ritmos diversos anunciados e intervenidos por los puntos suspensivos. Sin embargo, tal como lo analiza Raimondi, lo que hay en Punctum es una lengua objetivada, versiones de un sistema de la lengua y no una escucha de ciertas hablas (48). Entonces, claro, el uso del discurso indirecto se impone, pero lo que suena, aparece como mención, mediado por un saber más que por el mero oído: música incidental o "música sabiamente funcional", lo que se escucha en la radio del Citroën de los heavies -Iron Maiden-, cumbia o basura, como cuando Hielo dice: "sacá (...) esa basura/ clásica de la radio/ y poné heavy/ metal" (76 y 38). ${ }^{11}$ La escucha, entonces, en Punctum, está obturada o interferida:

El parlante roto, dice Guasuncho

hacía que la canción,

Blondie, se escuchara de a ráfagas, arrastrada

hasta la pieza desde otro lugar

menos pensado (Gambarotta: 10 )

Es llamativa la analogía entre la materialidad de esta escucha, la textura de aquello que suena y la imagen que elige Gambarotta en la entrevista realizada por Munaro para hablar de una lengua política como la de los 70, que aparece en Punctum: "Es como el sonido que emite una radio portátil molida a golpes con un bate de béisbol que capta señales de aquel momento en el presente. [...] la radio molida a palos que todavía capta y emite." (2011: s/n). Ese sonido entonces, la idea enlazada de que quien escribe está a la escucha, esa que Zelarayán plantea en Lata peinada, y a la vez, la convicción de que el poema capta algo de esa diatriba, que es la discusión política y que Gambarotta elige llamar ruido (2011: s/n), tiene su correlato en la arritmia y, en todo caso, se relaciona con lo que lúcidamente Ceresa llama imágenes "ruidosas" en Punctum, mezcladas, sin contornos fijos (645), como si se tratase del presente y el pasado bajo una versión trashera, sucia:

Trash es la hojarasca, broza, paja, escombros

basura, bajazo, deshecho

de este mundo o

un cualquiera, trashery y trashiness quieren decir lo mismo,

trashy es un despreciable, un inútil

y cómo no va a estar podrido

si el año que apenas empezaba se termina,

por la avenida del bajo pasan

las camionetas repartidoras de diarios

y los compañeros son todos unos cínicos. (Gambarotta: 24) 

textura, la del golpe como forma de puntuación auditiva. ${ }^{12}$ Se trata de un continuo que ha sido asociado a la idea de margen ${ }^{13}$ y que, sin embargo, no para de proliferar en su desmesura. Una lengua de sonido empastado, de retracción anafórica y a la vez de verbos remarcados con mayúscula que se suceden sin fin; un continuo que recibe potentes puntuaciones auditivas, entre las que podrían destacarse las jergas (sobre todo en la primera parte del libro) que hacen de eso que se dice un puro sonido: parka, palmazo, lonja, monkey, chatos, bazuco, sake, jale y las barras que cortan aleatoriamente el continuo, como la marcación gráfica de un espaciamiento en la escucha de quien escribe (apoyado en la tendencia a la elipsis o a la interrupción) y, a la vez, una respiración de quien habla, una percusión tonal. Porque lejos del registro de una lengua hablada con sus especificidades (hay, claro, un corte etario y de clase en ese diccionario), lo que se escucha es un tono que se aleja del murmullo o de la conversación y se acerca al grito o adquiere una velocidad inusitada. No solo porque "Caduguita lanza un grito de muerte funky" (11), sino porque es una lengua que vuelve para atrás, avanza y se corta:

pero aquí somos pacíficos/igual he clavado/ he chantado/

así el formón/ así noes que seamos hardcortitos así/ es que

igual se merecen un palmazo/ así nunca el Bronx así/ pero

el popero con monedas se escurre mal/ así que el otro día la Cala así/ fua/

perchó una parka así y dulce así/ pero pasó en un surco la chaveta así/ y quedó

tirada así

con olor a Neo y llena sangre y lonja así/ los tombos de chasca con ella adentro así/

pero es raro así/ nunca es tanto/ le pone

mucho la pesca así/ y no pasa nadie por la cuadra así/

aburrío así (....) (González: 13)

Toda una estigmatología, diría Szendy (2016: 12 y ss); los signos y ciertos significantes funcionan en la poesía de Yanko González como en Punctum de Gambarotta los puntos suspensivos que marcan lo que se abre como secuencia, pero también aquello que queda por fuera: un continuo interrumpido o un fragmento punzado, marcado por el ojo. En Metales pesados, incluso, sobresalen como un alerta. Casi como un asterisco, las palabras en mayúsculas, ciertas jergas que se identifican como tales, aunque no sepamos lo que significan, arman la textura de una lengua desatada y a la vez rota, sus momentos de máxima tensión. A veces es puro sonido y siempre está asociado lo corporal: "Vamos' -me dicen/ palabra que me topa el tímpano derecho" (17) ${ }^{14}$ y al movimiento como el de los videojuegos, el de ese Space invaders que envía a los ochenta y consiste en ir salvando obstáculos “ 'La bala no cruza/ hay un cabezón fantasma/ dispárale: la puerta roja/" “ (19) y que termina como estribillo de una lengua moldeada por el uso, marcada por la clase y las prácticas: "bein chichi suelta sota en er video" y finalmente cortada como una canción, puro ritmo:

Suertasota/ en er vieo/ bein Chichi/ en er video/ suerta ficha/

suerta sota/ Chichi en er video/ bein Chichi/ Chichi suerta/

suerta sota/ en er video/ por

$\mathrm{fa}$

(González: 20) 


\section{Maquetas políticas}

puntuación de una anterior e incluso de un territorio hacia el que va la poesía de la época: la ciudad. Esta tiene sus libros representativos en El Paseo Ahumada de Enrique Lihn y La ciudad, justamente, de Gonzalo Millán, o en El Solicitante Descolocado de Leónidas Lamborghini y en gran parte de la poesía de los sesenta argentina, incluso bajo su forma barrial. Pero se trata, en ambos casos, de una focalización máxima o más bien de un recorte.

21 Porque Puntcum abre delimitando un espacio, "un lugar sobre la calle" geometrizado. No basta decir que hay alguien en una habitación sino que esta es: "Una pieza/ donde el espacio del techo es igual/ al del piso que a su vez es igual/ al de cada una de las cuatro paredes" (7). Por su parte, Metales pesados (1998) marca una zona autónoma dentro de un mapa y lo que la caracteriza es su forma, el triángulo, nombre de la segunda parte del libro (y hace entrar, con mayor claridad, la mirada y el oído del antropólogo): "VAGUÉ por el triángulo sin estómago/ bajo ombligos y de cada tres al frentes/ uno era una arista venenosa donde se descomponían mis amigos/ esos vértices donde el triángulo esquina por sus fauces/" (26). Ambas espacializaciones pueden ser leídas como un punto de vista y un punto de audición, que simula ser el origen en Punctum y aparece como el lugar en que todos se pierden en Metales... No, no se trata de un laberinto sino más bien de una "maraña" (González: 26). El cubo inicial de la habitación, del interior que comparte uno de sus lados con el exterior parece ser el ejercicio de la tabula rasa que abrirá lo visual y la escucha donde el pasado y el presente conviven, o más bien donde los bloques de bordes menos precisos del pasado emergen alternativamente. Alternancia de presencia y ausencia en ese espacio que también se califica como "una cámara de agua sellada al vacío" (Gambarotta: 44). El Triángulo, es el lugar al que se llega después de los poemas de la primera parte: después de que aparezcan "LOS PISTOLS/ los Todos Por la Casa/ Los Cacho Cabra/" (15), "Las Tres Tribus" (10) y, sobre todo, después de que se mencionen el hip-hop, el metal, Depeche Mode, la música tecno, la cumbia, el punk-rock. Se llega aturdido, podría decirse, porque si hay algo que caracteriza Metales pesados, como hemos visto, es que se plantea un oído abierto.

Si lo primero que aparece en Punctum, es ese que "no sabe quién es" y va despertando para dar cuenta de "La ubicación lúcida/ del lugar en el día, el ruido,/ el cuerpo latiendo,/ la ruina de una idea que corre/ por una red de nervios,/ palabras de acero/ contenidas en un soplo:/ un orificio cabeza de alfiler/ en una cavidad del corazón." (7); quien lee llega al triángulo aturdido, y el antropólogo que va a observar a ese grupo de jóvenes de una zona santiaguina marginal llega sin aire ("BOQUIÉ": González 1998: 26)

¿Por qué me interesa este corte espacial, esta coincidencia de cortar extremadamente, casi una retícula en el que aparecerán los poemas, los cuerpos, las temporalidades del pasado o el puro presente, los fantasmas? Porque los pongo en contacto con otra conexión más entre estos dos libros: un modo de mirar, de decir lo político que, por afuera, en las entrevistas, aparece bajo el sesgo de la observación. Yanko González insiste en algunos reportajes en proponer Metales pesados como una indagación etnográfica en verso ${ }^{15} \mathrm{y}$, a su vez, Martín Gambarotta postula Punctum como "un análisis de situación en verso" (en Cortiñas 2009, s/n).

Cuadernos LIRICO, 23 | 202 
Experiencia etnográfica y análisis político de situación en verso. A partir de estas declaraciones podría pensarse cómo y qué puntúan, marcan, delimitan de lo político Martín Gambarotta y Yanko González, pero sobre todo el carácter doble de esta puntuación: hacia la tradición de la poesía política, de la poesía que se escribe situada en lo público, y hacia el análisis político o el relato etnográfico. En este sentido, la espacialización se torna relevante porque adquiere el carácter de maqueta: un cubo con sus ángulos como una cámara oscura y un punto de vista (el que despierta, el enfermo) con una posición más o menos central que abrirá fragmentos temporales de la historia política argentina, en un cruce entre los movimientos revolucionarios de los setenta y el neoliberalismo de los noventa; un triángulo cuyas aristas no dan lugar a un punto de vista o de escucha sino que son, en sí mismas, la condensación de lo sensible en esa zona de jóvenes chilenos marginados, de fines de los ochenta y principios de los noventa:

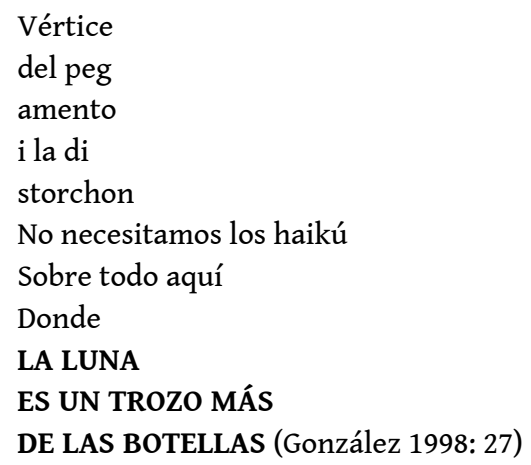

\section{Por una política "orgánica": el ojo y la boca}

Todo parece estar en una misma línea de visión en Metales pesados: no hay arriba y abajo (incluso cuando se usan las notas al pie). A la idea topográfica de "maraña" habría que agregar ahora aquello que ocupa el vértice, la droga y la distorsión. Ya desde el vértice se cortan las palabras, se segmentan: un punto que puntúa. Entre las drogas bajas y la chilenización de una lengua de uso cultural expandido, el inglés distortion y su derivado fonético. La idea de distorsión también aparece en Punctum de Gambarotta, no explícitamente, sino como borradura, como indeterminación. En este sentido puede leerse la expresión de deseos del cierre del poema: “(...) un andamio/ para que lo suban,/ que lo suban ahí". (87) en la que repica una anterior: "Ah, que el gancho de esa grúa en desuso/ me cace del paladar para poder/ sobrevolar la escena" (26).

La altura no se alcanza y la horizontalidad arma el punto de vista sesgado, fragmentario, descolocado (lo que se alcanza a ver); sin embargo en esta última cita, en la que Cadáver pide que el gancho de la grúa lo levante, propone que lo enganche del paladar (como a un pescado) y en esa mención podría leerse la imposibilidad de decir, de hablar e incluso de escuchar lo político, que solo aparece como una lengua que debe reorganizarse, como un código silenciado (tal como dice Raimondi: 58); se trata de la censura de la "lengua tabú" de los setentas, de la lengua revolucionaria (Selci: 159). Por su parte, promediando el final de Metales pesados, cuando el antropólogo se va y advierte "la reconocida equivocación de mi ojo ciego" (González: 50) cuelga al final de 
ese poema una cita de las tantas que puntúan los poemas de la parte superior de la página:

25) ESTE PÁRPADO QUE DICE ADIÓS

es el que llora

mordiendo el ojo (51).

Y entonces, otra vez la boca y el ojo se enlazan, porque hay un ojo que no vio pero fue, en este caso, arrebatado por las "hablas", por ese puro sonido que no puede dejar de escucharse en todo el libro.

En Punctum (1996) y en Metales pesados (1998) emerge una poesía política absolutamente distinta a las de los sesenta y los setenta: no aparecen los temas políticos ni su modalidad de arenga o discurso (Selci: 158); no aparecen las figuras como las del militante, el "héroe" o el hombre común; por supuesto, tampoco la figura idealizada del trabajador (y sus solapamientos en la figura del artista), ni siquiera figuras menos estereotipadas como las del mendigo o el trabajador desempleado, o el saboteador de la fábrica, o el vendedor callejero.

Podríamos retomar ahora esta división de lo sensible que se armaba como gag entre el poema de Seudo de Gambarotta y "mercat de flores", de Yanko González Cangas. Porque allí los asientos delantero y trasero del auto, escenificaban una crítica, a la vez que daban cuenta de la imposibilidad de ser una cosa o la otra: artista o trabajador. Tal vez, en estas figuras dobles de la boca y el ojo que aparecen en una relación dislocada, pueda volver a postularse una alianza entre ambas figuras, en tanto se trabaja artísticamente la escucha y la visibilidad política, sin estetizar y sin idealismos, en un poema que inventa un nuevo fraseo. Pero además, porque ese pase de asientos y roles en el auto es, en definitiva, un movimiento de cuerpos y tanto Punctum como Metales pesados abren lo político como experiencia marcada en y por los cuerpos, en la tensión conflictiva entre lo escuchable y lo visible.

Los cuerpos destrozados, como Cadáver, "una capa seca que recorre su cuerpo,/ amarillento, casi neutro, terso" (Gambarotta: 44), que además siente "Coágulos/ de bruma en la mente/ acolchada, calambres de hígado/ que nacen en los dientes/ pasan por los nervios de las encías/ y echan una raíz inextirpable/ en la tripa" (Gambarotta: 28), o como Gamboa, que aparece "con el tabique deforme/ -sangre en la encía,/ el tic de masticar/ con la boca vacía./ la mueca registrada,/ la lengua de reptil/ que separa la carne/ de las espinas" (68). Los cuerpos pasados de droga, como el que hace girar su anillo para acá y para allá en Metales...: "muerdo labio muerdo encía/ remuevo el seserío nuevamente" (González: 17), o el que entra a la zona de observación, y dice "VAGUÉ por el triángulo/ sin estómago/ bajo ombligos y de cada tres al frentes", y luego "HUNDí en ese entonces dentro de su dentro este par de cueros leporinos/ que el isósceles lambisqueaba como hiena/ vesícula/ vejiga/ uréter/ vena iliaca" (26). No se trata de figuraciones, de tipos sociales, tampoco de voces de la política, sino de cuerpos casi muertos (de fantasmas, podríamos decir en Punctum, o mejor, de espectros, como los designa Mario Cámara), de cuerpos ni neutros, ni tersos, sino destrozados, marcados por el ruido y por la ruina.

31 Creo que esta es una diferencia notable con la tradición de la poesía política; los cuerpos, la posición incluso de los cuerpos, los cuerpos en proceso de desaparición o los cuerpos de los jóvenes marginados del Triángulo permiten pensar en una fisiología política o en un modo de la experiencia política puntuada por los cuerpos y sus marcas, sus estigmas: desde el pasado de Punctum o el presente de Metales pesados los golpes, los 
cortes, los pinchazos, su visibilidad y su escucha (una verdadera auscultación en el caso de los poemas del último) son la instancia de despliegue de una experiencia política. Desde la casi ataraxia del personaje o los personajes de Punctum (la amnesia histórica y política que repone, como explica Raimondi, el drama de "una política social interrumpida": 49) hasta la hiperkinesia de los personajes del Triángulo en Metales.... que bailan, quiebran, se chutan, jalan, la política está punteada por lo orgánico. Lejos del dictum político de los sesenta argentinos, del discurso o de la oración; lejos de la oda política o la épica presente en la poesía de Neruda o del mismo Gelman. Lejos de la filosofía, de la sociología y alejándose incluso de una interpretación analítica del pasado o una antropología del mundo sensible, como la que postula Le Breton. El poema está puntuado en ambos casos por el cuerpo y, a la vez, da cuenta de unos cuerpos puntuados (golpeados, marcados) por lo político. En realidad son poemas que sobrepuntúan, como dice Szendy, "atomizan[n], pulveriza[n], granula[n] las frases y las formas" (2016: 176). Parten de una focalización extrema que puede asociarse a una maqueta de pruebas y sin embargo, se abren a todas las puntuaciones sensibles atravesadas por los cortes gráficos, por los cortes temporales múltiples, por la tensión entre los puntos que marcan y fijan una posición: el estado y lo que queda afuera del estado, el neoliberalismo y la dictadura, le etnografía, el análisis político y la poesía. En medio, los tatuajes, las músicas, las remeras con logos de bandas o de agrupaciones políticas: no un orden sino ese desorden.

Punctum y Metales Pesados, a su manera, escriben una poesía política situada desarmando todas las cláusulas de la tradición: el poema no despliega un saber o una dramatización de lo político sino, justamente, lo que quedó y lo que queda en el cuerpo de lo político como experiencia sensible.

\section{BIBLIOGRAFÍA}

Barthes, Roland, La cámara lúcida. Nota sobre la fotografía, Barcelona, Paidós, 1990. Traducción de Joaquim Sala-Sanahuaja.

Cámara, Mario, “Restos audibles: entre la poesía y la historia en Punctum, de Martín

Gambarotta", Travessia n 1, 2013, Florianopolis, p. 281-91.

Ceresa, Constanza, "Resonancias de la revolución en la poética de Martín Gambarotta", Bulletin of Hispanic Studies 93 no 6, 2016, Liverpool University, p. 635-652.

Cortiñas, Gabriel. “Entrevista a Martín Gambarotta”, Diario Clarín, Buenos Aires, 28 de abril de 2009. Consultado el 5 de mayo 2021.

Díaz, Marcelo, "El ladrido siniestro", VOX virtual n 4, Bahía Blanca, octubre de 2001. Consultado el 02 de mayo 2021.

Gambarotta, Martín, Punctum, Buenos Aires. Libros de Tierra Firme, 1996.

González, Yanko, Metales pesados, Santiago de Chile, Alquimia ediciones, 2016 [El Kultrún: 1998]. 
González, Yanko \& Araya, Pedro (selección y prólogo), Zur Dos. Última poesía latinoamericana, Buenos Aires, Paradiso, 2004. Posfacio a cargo de Edgardo Dobry: "Zeitgeist zurdo".

Hoefler, Walter, “Metales pesados: el centro marginal del lenguaje”, Revista Logos nº 10, 2001. Consultado el 2 de octubre 2020.

Le Breton, David, El sabor del mundo. Una antropología de los sentidos, Buenos Aires, Nueva Visión, 2009. Traducido por Heber Cardoso.

Mellado, Silvia, "Poetas y baquianos: los fragmentos de una historiografía de la literatura patagónica en prólogos de antologías de cuento y poesía publicadas entre 1991 y 2009”, Cuadernos del CILHA $16 \mathrm{n}^{\circ} 1,2015$.

Munaro, Augusto, "Martín Gambarotta: No se puede escribir poesía sin estilo" (entrevista a Martín Gambarotta). LosAndes.com (Especial para Cultura Los Andes), jueves 29 de septiembre de 2011.

Neira, Hernán, “Anestética de Metales pesados de Yanko González Cangas”, Revista de Estudios Filológicos nº 35, 2000, p. 207-221. Consultado el 2 de octubre 2020.

Patologías culturales blog. "Los textos y los libros son parte de un ruido ambiental, de discusiones y de trifulcas" (entrevista a Martín Gambarotta), 06 septiembre 2015. Consultado el 30 de abril de 2021.

Porrúa, Ana, “Punctum: sombras negras sobre una pantalla”, Boletín del Centro de Estudios de teoría y crítica literaria $\mathrm{n}^{\circ} 8$; Centro de Teoría y Crítica Literarias, Facultad de Humanidades y Artes, UNR, Rosario, octubre de 2000, p. 102-111.

--- "Mirar y escuchar: el ejercicio de la ambigüedad", Punto de vista ${ }^{\circ}$ 69, abril de 2001, p. 5-8.

---“"Retorno, resaca”, Punto de vista nº 82, Buenos Aires, agosto 2005, p. 44-47.

--- Caligrafía tonal, Buenos Aires, Entropía, 2011.

--- "Quién hace tanta bulla?: puntuaciones políticas de la voz y la escucha en la poesía latinoamericana”, Orbis tertius $25 \mathrm{n}^{\circ}$ 32, Uniersidad Nacional de La Plata, junio 2020, p. 25-32.

Quintana, Hugo (2004). “Poquita fe. Primer encuentro internacional de jóvenes poetas”. Revista $E l$ Hermitaño ${ }^{\circ}$ 5, Chile, noviembre 2004. Consultado el 5 de mayo 2021.

Raimondi, Sergio, "El sistema afecta la lengua. Sobre la poesía de Martín Gambarotta",

L/E/N/G/U/A/J/E/o, Madrid, septiembre 2017, p. 46-59.

Rancière, Jaques, El reparto de lo sensible. Estética y política. Santiago de Chile, Lom ediciones, 2009.

---. Aisthesis. Escenas del régimen estético del arte, Buenos Aires, Manatial, 2013. Traducción de Horacio Pons.

Rubio, Alejandro. "Una velada imperdible”, VOX virtual n 3, Bahía Blanca, septiembre de 2001. Consultado 2 de mayo 2021.

Ruiz, Felipe, "Detectives salvajes en la UPEC", Rocinante, Santiago de Chile, sábado 6 de noviembre 2004. Consultado el 2 de mayo 2021.

Selci, Damian, "Rompiendo la espiral de silencio", Postfacio a Seudo, Gambarotta, Martin. Seudo/ Dubitación, Bahía Blanca, Vox, 2013, p. 154-162.

Szendy, Peter, Escucha. Una historia del oído melómano. Buenos Aires: Paidós, 2003.

--- En lo profundo de un oído. Una estética de la escucha. Santiago de Chile, Metales pesados, 2015. 
--- A fuerza de puntos. La experiencia como puntuación, Santiago de Chile, Metales pesados, 2016.

\section{NOTAS}

1. Mucho antes que estas jornadas se hizo el "Encuentro de nuevos poetas latinoamericanos" (1999) en la ciudad de Santiago de Chile. Luego, entre los festivales que propiciaron las reuniones, vale citar el "Encuentro Internacional Chilepoesía" que comenzó en 2001 bajo la dirección de José María Memet y que en 2003 tuvo como invitado extranjero a Gambarotta; "Salida al mar" (2004-2011), en cuya coordinación permaneció siempre Cristian de Nápoli (en el de 2006 leyó Yanko González), del que se encuentra una descripción cronológica en https:// salidaalmar.wordpress.com/acerca/; el Festival chileno "Poquita fe" (2004, primera edición), entre cuyos coordinadores han estado Héctor Hernández Montecinos, Pablo Paredes, Carola Zuleta y Rodrigo Gómez; el "Festival Internacional de Poesía de Rosario" (1992, primera edición), que tuvo entre sus coordinadores de mayor permanencia a Osvaldo Aguirre, Martín Prieto y Daniel García Helder.

2. Es interesante, en este sentido, rescatar un pequeño ensayo de Marcelo Díaz en la Vox virtual nro. 4. Bajo el título "El ladrido siniestro", Díaz contesta a una nota de Alejandro Rubio que había salido en el nro. 3 de la revista, "Una velada imperdible", en la que comentaba, no sin ironía, las lecturas de Durand, Damián Ríos, Marcelo Díaz y Fernanda Laguna en La Casa de la Poesía, dirigida en aquella época por Daniel García Helder. Entre las críticas está la de la ambientación, que envía a la forma tradicional de la "velada" (una mesa, un velador, un poeta). Rubio escucha los poemas en tanto tales, dice cuáles le gustaron y cuáles no. En "El ladrido siniestro", Díaz esboza algunas apostillas al texto de Rubio que me parecen interesantes para lo que estoy desarrollando: "La luz retórica del velador retórico de la sala delimita un territorio que favorece el florecimiento de ciertos discursos y que va en desmedro de otros. Por ejemplo: Ríos flotó cómodamente en esa luz, su poesía de tono sereno, mate, reclama cierto sosiego para su lectura que el velador proveyó de manera conveniente. Durand, en cambio, bajo ese velador parecía un animal sedado.

Me acuerdo de Durand en el '90, en Santiago de Chile, en un bar-librería (que luego del paso del contingente poético argentino-chileno quedó convertido solamente en bar) declamando sobre una mesa, moviendo los brazos, doblándose como si trabajara con el cuerpo cada palabra, adentro, antes de que salieran de la boca. Me acuerdo del efecto poderoso de cada palabra lanzada así. Tengo presente, con nitidez, aquella lectura de hace once años atrás. Y entiendo entonces la objeción al velador. Y la comparto" (Díaz 2001: s/n).

3. Quisiera destacar la percepción de Hugo Quintana en una crónica sobre el primer encuentro del Festival "Poquita fe", en el 2004, publicado en noviembre de ese año en El hermitaño, porque hay algo de estas líneas de puesta en voz que, tal vez no casualmente, destaca como al pasar y sin todos los nombres: "El hermano Hlousek lee armado con un Sour, y Quezada vocifera encima del micrófono como si acaso estuviera rapeando. Zurita le pide a Gladys González que se lea otro poema, y al final el argentino aquel que va disminuyendo el tono de la lectura a medida que va avanzando -recuerdo fugazmente la maña de Poe por hablar cada vez más bajo para obligar a su interlocutor a poner, paulatinamente, cada vez más atención-" (2004: s/n).

4. Es interesante cómo se asocia a una dificultad este tipo de rasgos (y cómo el carácter narrativo de la poesía argentina se contrapone a una cualidad tonal de los poetas chilenos), cuando Felipe Ruiz hace una crónica del Festival de poesía latinoamericana "Poquita fe" 2004: “Ahí están, por ejemplo, la poesía argentina. Sus voces representantes (Germán Garrido, Marina Alessio, Cristian de Nápoli) vinieron a mostrar el peso que la tradición narrativa tiene en el país, peso que se ve reflejado en la propia poesía. El minimalismo de los recursos, la escasez de metáfora y una tendencia notoria a lo argumentativo, ofrecieron una poesía poco acostumbrada para el público 
nacional, tan habituado al verso vociferante y a la impostación. Los poetas argentinos demandan una atención particular, una lectura atenta y un clima de escucha casi ideal" (Ruiz 2004: s/n).

5. Szendy (2016), como Barthes, destaca los sentidos de la puntuación a partir de la etimología del término: punctum es pinchar, puntuar, picar, tatuar, y el término se relaciona con stigma, marca. Usamos en este caso el término estigma asociado a su sentido etimológico como una marca hecha a fuego. La estomatología que propone Szendy aborda los signos de puntuación tradicionales, pero también el golpe de la cámara de fotos, o la historia del estetoscopio en la historia de la escucha médica.

6. Se trata del Nro. 9 de la revista, de junio 1999. Poesía.com fue un sitio de internet en cuyo consejo editorial estuvieron, además de Gambarotta, Daniel García Helder y Alejandro Rubio. Además de las selecciones de textos, de los ensayos, publicaba habitualmente libros completos de poetas latinoamericanos, algunos recientemente publicados y otros, agotados e inhallables. Su primer número salió en noviembre de 1996 (el sitio aún se llamaba internauta), y el último, el número 14, en marzo de 2001.

También en 1999, Diario de poesía publique una selección de poemas de Metales pesados de Yanko González (Nro. 49, abril: p. 27) y luego, en 2001, se publica un anticipo de Alto Volta, con una selección de poemas (nro. 59).

7. En relación a las antologías como reunión de escrituras que dan a conocer la emergencia de ciertos poetas recientes chilenos/as y argentinos/as, a la vez que generan lazos que darían textura a puntos de contacto de poéticas latinoamericanas, agregamos que la versión en papel del número 4 de Vox (2001), traía en su interior, una antología, un libro de formato pequeño: Al Tiro. Panorama de la nueva poesía chilena bajo la selección de Germán Carrasco y Cristian Gómez; el mismo que presenta Marcelo Díaz en la Vox virtual y del cual hay allí una selección. El armado, tanto en la revista Vox como en poesía.com y, a su modo, en Diario de poesía, tiene la forma del anuncio, de la novedad, pero hace pie en las publicaciones. Una cualidad que puede rastrearse también en el número 9 de poesía.com, porque allí es el propio Yanko González el que selecciona una muestra de la poesía joven chilena y, además, porque se proponen lecturas cruzadas entre poetas chilenos/as y argentinos/as. Es Alejandro Rubio, en ese caso, el que lee Metales pesados (además de La insidia de los días, de Germán Carrasco) y, a su vez, Yanko González lee Música mala de Rubio (junto a Redondel de Romina Freschi). Claramente, hay algo de ilegibilidad en Metales... para Rubio y en Música mala para González. En esas diferencias, también se teje el vínculo entre poetas chilenas-chilenos y argentinas-argentinos.

8. Leemos en Punctum: “Así, en vez de hacerte el artista / buscate un oficio noble que te gaste las manos: / carpintero corta madera. Cambia madera / formada por sus manos y herramientas / por plata. Plata por madera / no ideas por madera. Plata / por una silla trabajada / con tus manos" (55).

9. Los poemas de Gambarotta citados en esta sección pertenecen todos a Punctum y los de Yanko González Cangas, a Metales pesados, por esa razón se consignará solamente, en ambos casos, apellido y número de página.

10. En Punctum, Cadáver tiene que ponerse "gotas para los ojos,/ que obnubilan la vista,/ dejan la visión acuosa" (40) y lo hace para que "los ojos en sangre vuelvan a blanco" (41). Una visibilidad que detecta texturas cuando la oscilación entre vigilia e inconciencia es la del pasaje "-entonces está despierto./ Las manchas de óxido en el cielo-/ el color de la luz sobre las cosas, el cielo/ que se retrae y es óxido borroneado", o cuando los personajes caminan "en la mañana grumosa" (36). 11. Los momentos de escucha más clara, en Punctum, están asociados a Manolito, el personaje mexicano de El Gran Chaparral (una serie televisiva norteamericana de gran difusión en Argentina, pero que data de fines de los setenta) cuando toca su guitarra y canta temas de amor que dicen por ejemplo "cuando Ruth viene a verme a mi laguna honky-tonk" o "nena estoy cansado de cabalgar sacame las botas/ en tanto que más atrás una fila de indios Navajo/ se mece de un lado a otro haciendo corito/ -uuuuuuuuuuhhhhhh, sacame las botas" (Gambarotta: 14). Un sonido del 
pasado, un contrapunto perfecto en su inversión con la lengua revolucionaria de los setenta que no aparece como tal en el libro: como un resto cuya presencia organiza esa falta. Por otra parte, y en relación al punk distinguido en algunos nombres, Sid Vicius, Iggy Pop, Lou Reed, o al heavy metal podría decirse que se plantean, más que como sonido, como articulación de una lengua, la de Cadáver, "tu castellano punk", "palabras irreversibles" (82).

12. Desarrollé esta idea en “'¿Quién hace tanta bulla?’: puntuaciones políticas de la voz y la escucha en la poesía latinoamericana" (2020).

13. Dice Hernán Neira: "Metales pesados [...] está centrada en las tribus de jóvenes marginales urbanos, a los que describe de modo hiperrealista", "situándose al centro de la polémica platónica relativa al lugar del poeta dentro de la polis, o quizás la tribu, de los etnógrafos rodeados por la marginalidad urbana siendo ellos marginales en la epistemología de las ciencias posmodernas [...]. Opone la anestética de lo marginal a la estética de lo bello" (2000, s/n). Y Walter Hoefler: "Sospechamos que se trata de un programa de etnopoesía (dado el epígrafe de Evans-Pritchard que abre Metales pesados), como "un viaje al centro marginal del lenguaje" (2001, $\mathrm{s} / \mathrm{n})$.

14. En el mismo sentido lo que se ve "topa", percute, el ojo: "Lear se puso a un lado/ observando como el luchador 1 del game pateaba el centro de su córnea/ y la cara brillante con el destello de los golpes/": 68

15. Hablando de Metales pesados, Yanko González cuenta entre las lecturas que funcionaron como antecedentes, las de algunos antropólogos y poetas y suma "otras «lecturas» que no tienen soporte escrito, más bien oral, visual, olfativo, sonoro: aquella realidad del cual observé participando". Luego agrega: "Es una muestra parcial de la resolución que fue tomando mi experiencia etnográfica centrada en un borde: subjetividad joven excluida social y culturalmente desde fines de los 80' hasta principios de los 90'. Son destellos de una totalidad que revela en forma atomizada el «estilo de vida» de un segmento de la juventud chilena urbano popular finisecular". Y agrega: "propone como antecedentes lecturas de antropólogos, de poetas, pero también "otras "lecturas" que no tienen soporte escrito, más bien oral, visual, olfativo, sonoro: aquella realidad del cual observé participando" (González 2000: s/n).

\section{RESÚMENES}

Nos proponemos leer un momento de cruce de la poesía chilena y la poesía argentina que se recorta sobre el dictum político específicamente. Se trata de una modulación extrema que abordaremos focalizando en Punctum de Martín Gambarotta (Buenos Aires, 1968) y Metales pesados de Yanko González Cangas (Buin, Chile, 1971). Estos libros serán leídos como escenas ópticas y acústicas, como "pequeñas máquinas" a partir de las cuales pueden revisarse nuevas formas de lo sensible (Rancière 2013 y 2009), es decir, nuevos repartos del espacio, la palabra y la mirada en el orden de la poesía política, y también en relación con algunos hitos de la poesía latinoamericana.

Le propos de cet essai est de lire un moment où la poésie chilienne et la poésie argentine croisent leurs chemins, sur le fond du dictum politique. Il s'agit d'une modulation extrême, qu'on abordera en focalisant sur Punctum, de Martín Gambarotta (Buenos Aires, 1968) et Metales pesados, de Yanko González Cangas (Buin, Chili, 1971). Ces livres seront lus comme des scènes optiques et 
acoustiques, comme des "petites machines" à partir desquelles des nouvelles formes du sensible (Rancière 2013 et 2009) peuvent être pensées, c'est-à-dire des nouveaux partages de l'espace, de la parole et du regard aussi bien dans l'ordre de la poésie politique, que en relation avec quelques points culminants de la poésie latino-américaine.

Our proposition is to read a certain moment of Chilean and Argentine poetry, specifically through the notion of political dictum. We will address what we consider an extreme modulation, focusing on Martin Gambarotta's (Buenos Aires, 1968) Punctum and Yanko González Cangas's (Buin, Chile, 1971) Metales Pesados (Heavy Metals). We will read these books as optical and acoustic scenes, as "little machines" from which new forms of the sensible (Rancière 2009, 2013) can be analyzed, that is to say, as new distributions of the space, the status of the word and the nature of the gaze in the context of political poetry, as well as in relation to some turning points in Latin American poetry.

\section{ÍNDICE}

Mots-clés: poésie politique, l'écoute, le regard, ponctuation

Keywords: Political poetry, Hearing, Looking, Punctuation

Palabras claves: poesía política, escucha, mirada, puntuación

\section{AUTOR}

ANA PORRÚA

porruana@gmail.com

CONICET/ INHUS/ CELEHIS/ UNMDP 